\title{
The Efficiency Estimation of Management Control of Tax Calculations and Obligations in the Organization Management
}

\author{
V.A. Piskunov ${ }^{1}$ and A.Yu. Smagina, ${ }^{2, *}$ \\ *Corresponding author: anastasiasmgn@ rambler.ru \\ ${ }^{1}$ Samara State University of Economics, Samara \\ ${ }^{2}$ Togliatti State University, Togliatti, Russia
}

\begin{abstract}
With the increase of information received every day and the speed of decision-making, management control is becoming one of the most important mechanisms in the system of managing assets, capital and obligations of an organization, ensuring stability, development and economic security. Nowadays, there is an increasing interest of internal users in the process of forming and controlling tax calculations and obligations for the purposes of tactical and strategic management.

Further development of the management control of tax calculations and the obligations of an organization largely depends on the development and selection of methods for evaluating its effectiveness. To date, in the economic literature and in practice there is no unified approach to the selection of criteria and indicators for evaluating the management control of tax calculations and obligations. In the opinion of the authors, as criteria that characterize the management control of tax calculations should be used performance and reliability.

The purpose of the study is to develop a methodology for assessing the effectiveness of management control of tax calculations and liabilities, which allows to ensure the confidence of internal interested users in the accuracy of the information reflected in accounting and reporting, and also in compliance with the implementation of control - compliance of the implementation of management control with established internal requirements. To solve the problem of developing a methodology for assessing the effectiveness of management control of tax calculations and obligations, the following methods were used in the study: systematization, modeling, method of complexity and dialectical method.

For the purpose of providing interested users with complete and detailed information on the effectiveness of management control of tax calculations and obligations, it was proposed to disclose its reliability through a system of quality indicators, and the performance through systems of both quality and quantity indicators.
\end{abstract}

Keywords: efficiency, management control of tax calculations and liabilities, performance evaluation, reliability assessment.

\section{Introduction}

In the conditions of the formation of an innovative type of economy and intensification, the management control of tax calculations and obligations is becoming increasingly in demand, which makes it possible to reduce the likelihood of tax risks for organizations. The problem of organizing management control and its information support in the organization's management system has been studied from different angles - in assessing the level and revealing of reserves for reducing costs, from the standpoint of assessing the actual effectiveness of financial investments, in working out issues of the expediency of recognizing expenses and attributing them to a specific period of time. At the same time, many issues still remain unresolved and are debatable. These include, in particular, the issue of evaluating the effectiveness of management control in general and, in particular, the control of tax calculations and obligations. Especially acute lack of information on the effectiveness of control began to appear in the conditions of the development of market relations and the growing competition between producers. Issues of calculating indicators for assessing management control are currently not well understood. More often in the economic literature attempts are being made to determine indicators of the effectiveness of managerial labor as a whole. Since management control is one of the functions of the management system, the authors consider it legitimate to use the existing methods of assessing management effectiveness to assess management control of tax calculations and liabilities.

The method of determining the economic efficiency of managerial labor, based on an assessment of three indicators, has become quite widespread: the amount of profit per employee of the administrative apparatus; the efficiency of the use of working time by employees of the management staff (the ratio of profits to the working hours of the management staff) cost-effectiveness of the maintenance of management personnel (profit related to the cost of maintaining the management apparatus). However, while this method, according to the authors, is inherent in a number of disadvantages. First, it is often impossible to determine the amount of resource savings, as well as the amount of losses resulting from the work of a separate structural unit of the management apparatus. Secondly, this methodology does not allow assessing the role of each division of the management apparatus in achieving the overall result of the organization's activities. 


\section{Problem Statement}

The studies of the organization and implementation of management (internal) control are devoted to the works of such scholars as M.V. Melnik et al. [1], S.A. Khmelev [2], Al Sawalqa, F., Qtish, A. [3], S. Gschwantner \& M.R. Hiebl [4]. The theoretical and methodological problems of evaluating managerial (internal) control were investigated in the works of such economists as V.A. Piskunov, V.A. Manyaeva et al. [5], M.A. Azarskaya [6], T.Y. Serebryakova et al. [7] and others. V.A. Piskunov, exploring the issues of evaluating the effectiveness of management control, proposes to highlight the effectiveness and the calculated amount of expenses for the implementation of such control as part of its evaluation criteria [5]. V.A. Manyaeva in her studies indicate the need to apply the main, in their opinion, evaluation criterion, expressed through performance [5].

M.A. Azarskaya proves that management control should be assessed by assessing the effectiveness of its design and the operational effectiveness of management control [6]. T.Yu. Serebryakova proposes to take as a basis two criteria for evaluating the effectiveness of management control, to which it refers to the effectiveness and efficiency, expressed through a set of qualitative and quantitative indicators of evaluation [7].

Based on the presented opinions of scientists, it can be concluded that there is no consensus in the scientific literature regarding the solution of the problem of evaluating the effectiveness of management control, including tax calculations and obligations, in terms of assessing the accuracy and completeness of presentation to interested users not only information about fait accompli, but also strategic information.

\section{Research Questions}

Considering the need for further scientific and practical development of the formation of a methodology for assessing the management control of tax calculations and obligations, the main areas of research in this article are the following:

- study of indicators characterizing the reliability and effectiveness of management control of tax calculations and liabilities;

- study of the transformation of qualitative indicators of management control evaluation into quantitative for the possibility of forming conclusions about the effectiveness of this system.

\section{Purpose of the Study}

According to the designated problem statement, the purpose of this study is to develop a methodology for assessing the effectiveness of management control of tax calculations and liabilities, which helps to ensure the confidence of internal interested users with regard to the following:

- compliance with the implementation of management control established internal requirements,

- completeness and accuracy of information about the object of control, formed in the accounting system and reflected in the reporting, as well as information of a promising nature for the purposes of making current and strategic management decisions.

\section{Research Methods}

To solve the problem of developing a methodology for assessing the effectiveness of management control of tax calculations and obligations, the following methods were used in the study:

- systematization - collecting and streamlining information from the scientific literature and other sources, which led to the conclusion that there is no methodology for assessing the effectiveness of management control of tax calculations and obligations, covering not only current and retrospective, but also strategic information for the purposes of making tactical and strategic management decisions;

- modeling - building a model for evaluating the effectiveness of management control of tax calculations and liabilities; - the method of complexity - the study and proposal for the implementation of the assessment of the effectiveness of management control of tax calculations and obligations based on an integrated array of information about this object: a retrospective, current and strategic nature;

- dialectical method - the study of the content of the concepts "reliability of management control of tax calculations and obligations" and "performance of management control of tax calculations and obligations" as the basis for assessing the effectiveness of such control. 


\section{Findings}

Based on the analysis of theoretical, methodical and practical experience in evaluating the effectiveness of management control, it was established that, with regard to management control of tax calculations and obligations, it should be done through an assessment of reliability and performance indicators. According to the authors of this study, these characteristics most fully allow us to assess the quality and effectiveness of the implementation of management control.

The reliability of management control of tax calculations and obligations is proposed to understand the system of indicators with which the interested user can get an idea about the organization and implementation of this type of control, as well as the correlation of control procedures with established goals and objectives of control. The performance of management control of tax calculations and liabilities is understood by the authors of the study as a positive impact on tax calculations and liabilities as an object of control, which is achieved by using control procedures. Assessment of the reliability and performance of management control of tax calculations is proposed to implement by using quantitative and qualitative indicators. For the purposes of this study, quantitative indicators are numerical data that are expressed in terms of calculated coefficients for assessing the correctness of certain processes and the tax system of a commercial organization, and qualitative indicators are indicators that are used to characterize the organization and management control of tax calculations and liabilities, as well as control procedures. It should be noted that qualitative indicators can be transformed into quantitative, using estimated coefficients, if it is necessary in the framework of strengthening the informativeness of the results of evaluating the effectiveness of management control of tax calculations and liabilities.

Evaluation of the reliability and performance of management control through qualitative and quantitative indicators occurs in accordance with the model presented in Fig. 1.

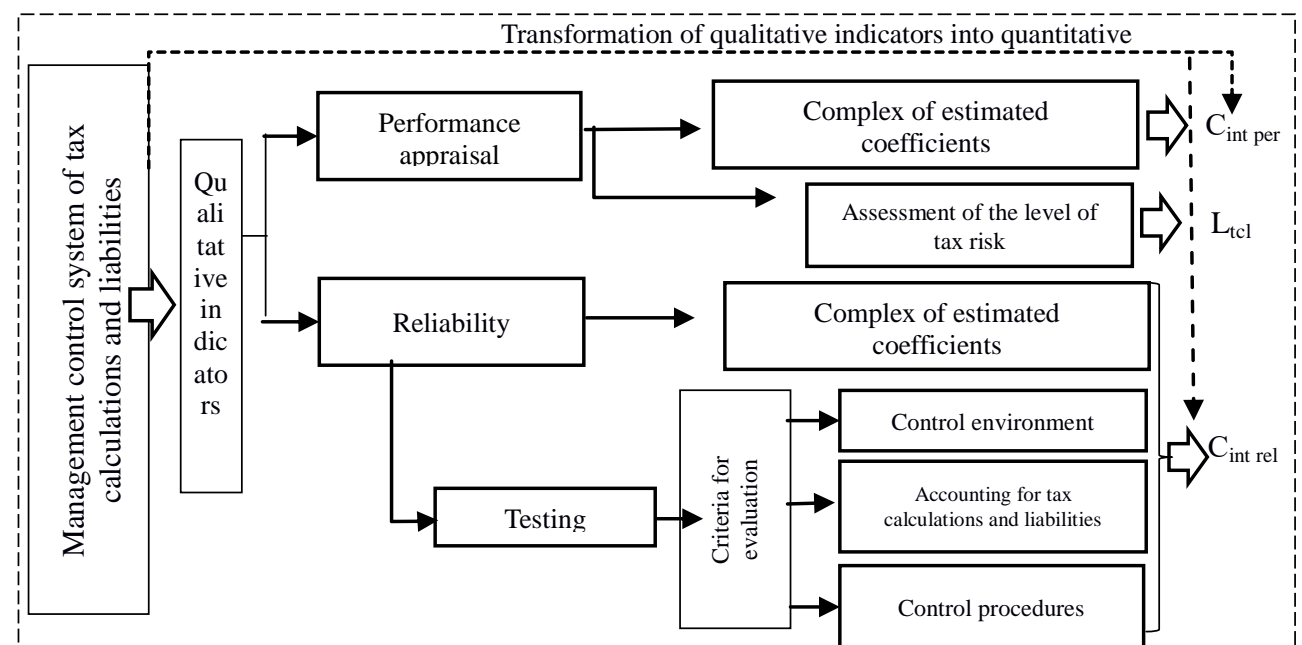

Figure 1. A model for assessing the reliability and performance of management control of tax calculations and liabilities (Source: compiled by the authors)

Evaluation of management control of tax calculations and liabilities by monitoring the reliability of such a system is performed using the following techniques: observation by a specialist responsible for assessing management control of tax calculations and liabilities, for the implementation of the control procedure; repetition of the control procedure; testing, which allows to determine the quality of control implementation (including testing of specialists responsible for the implementation of management control, and users of its information). In the framework of this study, using testing, it is proposed to assess the reliability indicators of the following areas: the control environment of management control of tax calculations and obligations; accounting of tax calculations and liabilities; control procedures as an element of management control of tax calculations and liabilities. In order to test the reliability of management control of tax calculations, it is necessary to rank in points the answers to the questions of each of the blocks proposed by the authors.

The authors of this study propose based on the obtained test results to use the developed evaluation factors for each of the three test blocks, determined by the weighted average formula and presented in Fig. 2. 


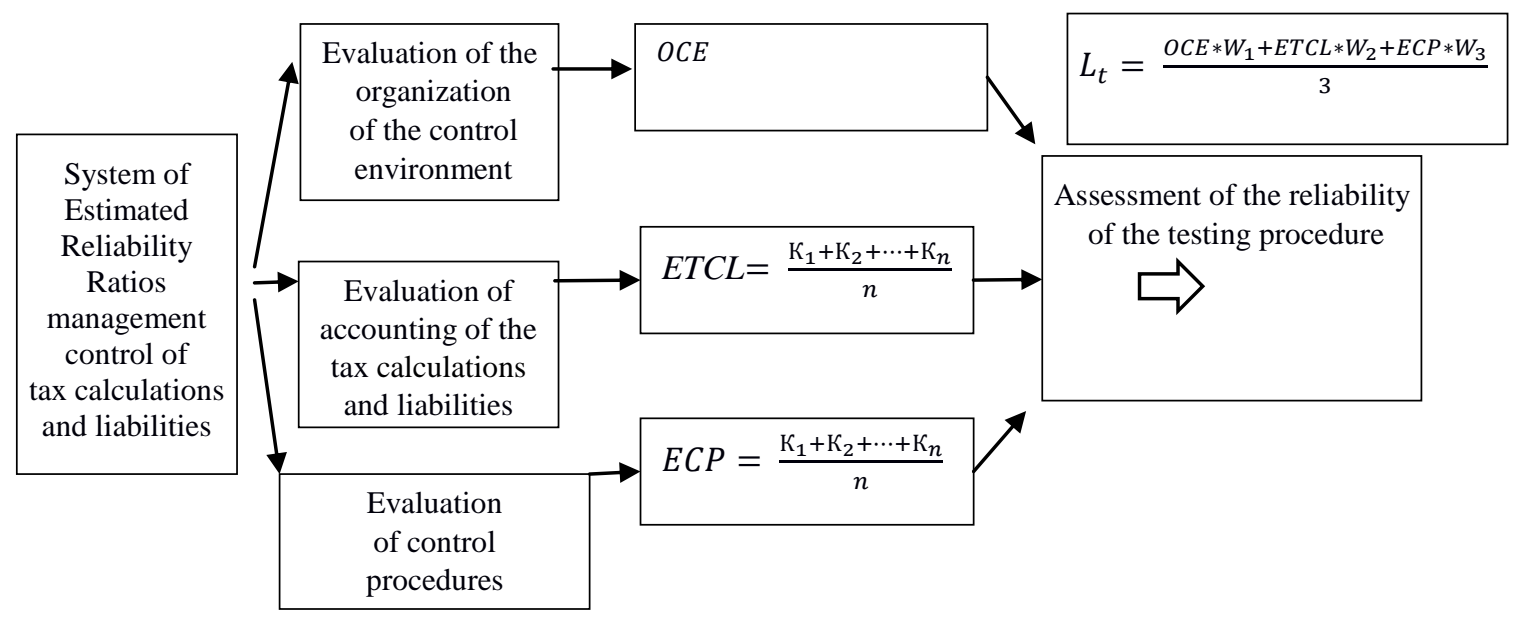

Figure 2. The system of estimated reliability factors management control of tax calculations (Source: compiled by the authors)

Indicators of OCE, ETCL, ECP should strive for a unit - in this case their value will be considered normal. After calculating the average weighted for each of the three testing blocks, assessing the reliability of management control of tax calculations and obligations, the authors suggest ranking the significance of the results of such tests (W1, W2, W3). The value of indicators of significance allows you to adjust the value of each estimated coefficient (OCE, ETCL, ECP) and calculate the new weighted average - the level of reliability of management control of tax calculations and liabilities according to the formula developed by the authors and reflected in Fig. 2. The value of the calculated level of reliability $\left(\mathrm{L}_{\mathrm{t}}\right)$ should also aim for a unit. Testing the reliability of management control of tax calculations and obligations is one of the components of the integral reliability coefficient developed by the authors for completeness of the qualitative characteristics of the reliability of such control. All components of this coefficient are presented in table 1.

Table 1. The coefficients of the qualitative assessment of the reliability of management procedures for tax calculations and liabilities

\begin{tabular}{|c|c|c|}
\hline $\begin{array}{l}\text { Components of the } \\
\text { integral coefficient }\end{array}$ & Integrated indicators & Formula \\
\hline $\begin{array}{l}\text { 1. Defining management } \\
\text { control procedures for tax } \\
\text { calculations and liabilities } \\
\text { that are used }\end{array}$ & $\begin{array}{l}\text { The ratio of the number of managerial } \\
\text { control procedures for tax calculations } \\
\text { and liabilities that are used or not used } \\
\text { to the total number of managerial } \\
\text { control procedures for tax calculations } \\
\text { and obligations }\end{array}$ & $C_{1 r}=\frac{P_{\text {used }} / \text { not used }}{P}$ \\
\hline $\begin{array}{l}2 . \quad \text { Monitoring the } \\
\text { implementation of } \\
\text { documenting management } \\
\text { procedures for tax } \\
\text { calculations and liabilities }\end{array}$ & $\begin{array}{l}\text { The ratio of the number of managerial } \\
\text { control procedures for tax calculations } \\
\text { and liabilities documented to the total } \\
\text { number of managerial control } \\
\text { procedures for tax calculations and } \\
\text { obligations }\end{array}$ & $C_{2 r}=\frac{P_{d o c}}{P}$ \\
\hline $\begin{array}{l}\text { 3. Testing (reliability) of } \\
\text { management control of } \\
\text { tax calculations and } \\
\text { obligations }\end{array}$ & $\begin{array}{l}\text { Reliability of management control of } \\
\text { tax calculations and obligations based } \\
\text { on the results of tests of three blocks }\end{array}$ & $\begin{array}{l}L_{t}= \\
\frac{O C E * W_{1}+E T C L * W_{2}+E C P * W_{3}}{3}\end{array}$ \\
\hline
\end{tabular}

Source: compiled by the authors.

The integral reliability factor of the management control of tax calculations and liabilities $\left(\mathrm{C}_{\text {int rel }}\right)$ is proposed to be calculated according to formula 1:

$$
\mathrm{C}_{\text {int rel }}=\sqrt[3]{C_{1 r} * C_{2 r} * L_{t}}
$$

When the value of this ratio, approaching the unit, the reliability of the system of management control of tax calculations and liabilities is qualified as high.

Evaluation of the effectiveness of management control is based on the determination of the fact of achievement or non-achievement of established (budget) indicators and the goals of the organization. Quantitative assessment of performance is based on the calculation of the two components of the integral coefficient proposed by the authors of the study for use (Table 2). 
Table 2. The coefficients of a quantitative assessment of the performance of management control of tax liabilities

\begin{tabular}{|l|l|c|}
\hline \multicolumn{1}{|c|}{$\begin{array}{c}\text { Components of the } \\
\text { integral coefficient }\end{array}$} & \multicolumn{1}{|c|}{ Integrated indicators } & Formula \\
\hline $\begin{array}{l}1 . \quad \text { Accuracy of } \\
\text { budgetary indicators for } \\
\text { tax liabilities for a set of } \\
\text { contracts }\end{array}$ & $\begin{array}{l}\text { The ratio of actual tax liabilities for } \\
\text { the reporting period to the total } \\
\text { budget tax liabilities }\end{array}$ & $C_{1 p}=\frac{T L}{T L_{\text {budget }}}$ \\
\hline $\begin{array}{l}2 \text { Accuracy of } \\
\text { budgetary indicators for } \\
\text { tax obligations for a } \\
\text { specific contract }\end{array}$ & $\begin{array}{l}\text { The ratio of the actual amount of tax } \\
\text { liabilities for the reporting period } \\
\text { under a specific contract to the } \\
\text { amount of budget tax liabilities under } \\
\text { the same contract }\end{array}$ & $C_{2 p}=\frac{T L_{\text {conract } A}}{T L_{\text {budget } \text { contract } A}}$ \\
\hline
\end{tabular}

Source: compiled by the authors.

Indicators for assessing the management control of tax calculations and liabilities are components of the integral performance coefficient $\left(\mathrm{C}_{\text {int per }}\right)$, which is proposed to be calculated using formula 2 .

$$
\mathrm{C}_{\text {int per }}=\sqrt[2]{\mathrm{C}_{1 \mathrm{p}} * \mathrm{C}}
$$

The magnitude of the components of the integral coefficient, as well as the coefficient itself, should tend to unity. The more they approach the 1, the more effective is the management control of tax calculations and liabilities. For the completeness of the characteristics of the effectiveness of management control, it is proposed to evaluate it also through a qualitative indicator by identifying changes in the level of tax risk of the organization. The calculation of the level of tax risk $\left(L_{T L n}\right)$ is proposed to produce the following formula 3:

$\mathrm{P}_{1,2, \mathrm{~N}}-$ probability of tax risk

$$
\mathrm{L}_{\mathrm{TLn}}=\frac{\mathrm{P}_{1} * \mathrm{I}_{1}+\mathrm{P}_{2} * \mathrm{I}_{2}+\ldots+\mathrm{P}_{\mathrm{N}} * \mathrm{I}_{\mathrm{N}}}{\mathrm{n}}
$$

$\mathrm{I}_{1,2, \mathrm{~N}}-$ tax risk exposure

To identify changes in the level of tax risk, it is necessary to compare its planned value or the value of previous reporting periods with the actual indicator. Positive dynamics testifies to the effectiveness of the implementation of management control of tax calculations and liabilities from the standpoint of quantitative assessment and ensuring the tax security of an economic entity.

\section{Conclusions}

Thus, the problem of the lack of a methodology for evaluating the effectiveness of management control of tax calculations and obligations, ensuring the confidence of interested internal users in the correctness, quality and feasibility of such control, taking into account not only current and retrospective, but also strategic information, is solved by assessing the reliability and effectiveness of such system.

The use of the methodology for evaluating the effectiveness of management control of tax calculations proposed by the authors of this study allows you to form a representation of interested users about the proper organization and implementation of management control, compliance with established rules and regulations, which guarantees their confidence in ensuring the tax security of an economic entity and is an information base for making decisions regarding improving the management of organizations.

\section{References}

1. M.V. Melnik, L.S. Panteleev, A.L. Zvezdin, Audit and Control. Moscow: Knorus (2007). [in Rus.].

2. S.A. Khmelev, Organization of internal control at the enterprise. Economics and Management, 11(49), 56-59 (2009). [in Rus.].

3. F. Al Sawalqa, A. Qtish, Internal control and audit program effectiveness: Empirical evidence from Jordan. International Business Research, 5(9), 128-137 (2012).

4. S. Gschwantner, M.R.W. Hiebl, Management control systems and organizational ambidexterity. Journal of Management Control: Zeitschrift für Planung und Unternehmenssteuerung, Springer, 27(4), 371-404. DOI: 10.1007/s00187-016-0236-3 (2016).

5. V.A. Piskunov, V.A. Manyayeva, T.E. Tatarovskaya, E.Y. Bychkova, Risk-oriented internal control: the essence, management methods at small enterprises. IEJME: Mathematics Education, 11(7), 2710-2731 (2016).

6. M.A. Azarskaya, The system of internal control in the management of organizations. Innovative Development of the Economy, 2(19), 111-118 (2014). [in Rus.]. 
7. T.Yu. Serebryakova, O.Yu. Kurtaeva, Internal control and controlling: concept-based specifics. International Accounting, 26(368), 2-12. URL: https://cyberleninka.ru/article/n/vnutrenniy-kontrol-i-kontrolling-kontseptualnyeosobennosti (2015). [in Rus.]. 